\title{
Sedation in Pediatric Patients: Assessment of Pediatric Knowledge
}

\author{
Maria Mariquinha Dantas Sampaio, ${ }^{1,2}$, Lídia Audrey Rocha Valadas ${ }^{3, *}$, Edilson Martins Rodrigues Neto ${ }^{3}$, Thais Gimenez ${ }^{4}$, José Carlos \\ Pettorossi Imparato5 , Ana Flávia Bissoto Calvo5, Patrícia Leal Dantas Lobo ${ }^{1,3}$ \\ 'Cearense Academy of Dentistry, Fortaleza, CE, BRAZIL. \\ 2University Center Dr Leao Sampaio (UniLeão). Juazeiro do Norte, CE, BRAZIL. \\ ${ }^{3}$ Pharmacy, Dentistry and Nursing College, Federal University of Ceara, Fortaleza, CE, BRAZIL. \\ ${ }^{4}$ Master of Science Program, Ibirapuera University, São Paulo, SP, BRAZIL. \\ 5São Leopoldo Mandic College of Dentistry, Campinas, SP, BRAZIL.
}

\begin{abstract}
Objectives: This study aimed to evaluate the knowledge of Pediatric Dentists in the city of Fortaleza-CE about the practice of sedation. Methods: Participated 66 professional's specialists registered in the Regional Council of Dentistry - Ceara who worked in public and private service. Data collection was performed through a structured and self-administered questionnaire. The data obtained were tabulated in the IBM SPSS Statistics program and analyzed through a descriptive and exploratory statistical analysis. Results: The results showed that $36.4 \%$ of the professionals had 5 to 10 years of specialization, $93.9 \%$ were female and $59.1 \%$ both worked in the public and private sectors. Only $21.1 \%$ had a sedation course and $33.3 \%$ used the technique. Midazolam and Cloral Hydrate were the most commonly cited drugs in the sedation technique. Allergic reactions were the most reported as risk of sedation. Conclusion: Considering the limitations
\end{abstract}

of this study, it is possible to consider that the professionals have reasonable knowledge and few use the technique of sedation, mainly because they do not feel safe.

Key words: Pediatric Dentistry, Anxiety, Sedation, Sedation in pediatric patients, Anxiolytics.

Correspondence

Prof. Lídia Audrey Rocha Valadas,

Department of Pharmacy, Dentistry and Nursing College, Federal University of Ceara, Fortaleza, CE Capitao Francisco Pedro, Fortaleza-60430370, BRAZIL.

Phone: +558533668000

Email: lidiavaladas@gmail.com

DOI: 10.5530/jyp.2019.11.78

\section{INTRODUCTION}

Fear and anxiety are interdependent and consist on the main barrier that dentists face when setting up a favorable working relationship during treatment with pediatric patients. ${ }^{1}$ The dental office is a highly anxious place and the treatment, in many circumstances, is characterized by a high stress situation, ${ }^{2}$ representing in some cases a huge challenge for both the child and the professional. ${ }^{3,4}$

Control of child behavior can be achieved through basic and advanced techniques. ${ }^{5}$ There are several management strategies for the pediatric patient that have been used during dental procedures, such as behavioral techniques, oral sedatives, inhaled nitrous oxide $\left(\mathrm{N}_{2} \mathrm{O}\right)$ and general anesthesia. ${ }^{6}$ In cases in which the behaviors pertinent to psychological conditioning are not effective to achieve the desired understanding and cooperation, the professional can use the pharmacological resources available. ${ }^{5}$ The drugs and the dosage involve therapeutic regimens that vary significantly, one can cite the use of the benzodiazepines and the nitrous oxide. ${ }^{7-11}$

The administration of these drugs promotes different levels of sedation. Moderate sedation is understood as a degree of minimal depression of consciousness in which the patient responds intentionally to verbal commands with or without slight tactile stimulation. This phase the indicated one for execution of the dental procedures in ambulatory environment. ${ }^{12,13}$

When different behavior management techniques protective stabilization, moderate sedation and general anesthesia are compared, children who receive moderate sedation during dental care present positive behavior in subsequent treatment sessions. Thus, it is required that Pediatric Dentists receive appropriate training to perform sedation. ${ }^{14}$

Some countries, such Brazil, the use of sedation in clinical practice by dentists is still not common, mainly due to the deficiency in its formation in relation to these drugs. There is even greater fear in Pediatric Dentistry. ${ }^{11}$

In the literature, there are few studies about what pediatric dentists think of and know about sedation. Therefore, it is necessary to investigate these subjects in the search to solve existing gaps involving this theme. ${ }^{15}$

In view of the above considerations, given that there is a limitation for Pediatric Dentistry to provide care for anxious children who do not respond positively to child behavior management techniques, this study aims to observe, through a questionnaire, the knowledge of pediatric dentists regarding the practice of sedation in the dental care for children.

\section{MATERIALS AND METHODS}

This is a transversal study, carried out in the city of Fortaleza, Brazil. This study was approved by the Research Ethics Committee under No. $246.435 / 2013$. The subjects were included dentists with postgraduate studies in Pediatric Dentistry who agreed to participate in the research. The local council, Regional Council of Dentistry (CRO-CE) was contacted for the identification of professionals enrolled in Pediatric Dentistry, with a total of 142 professionals registered at the time of the research. The board itself emailed the instrument to all those Pediatric Dentists. After that, all 142 subjects were contacted. A single researcher applied 
the questionnaires, after the initial clarifications talking about the objectives of the study, how to fill out and signing the Informed Consent Form (ICF), the participants answered the questionnaire without any previous consultation and immediately delivered the researcher.

The research instrument consisted of 13 multiple choice questions that addressed the following: profile of respondents as time undergraduate specialization, professional exercise time in Pediatric Dentistry and gender (Questions 01-03); professional activity in the workplace (Question 4); behavior and expectations of Pediatric Dentists in relation to the care of patients of difficult control, involving the main conducts chosen (Question 5) and the non-pharmacological techniques most applied (Question 6); professional qualification, courses on sedation (Question 7), the practice of sedation in their workplace (Question 8), felt secure in doing so (Question 9), the main drugs most prescribed (Question 10) and how often they would have been used (Question 11); knowledge about sedation: the main advantages and disadvantages (Question 12) and what are the most relevant risks that would be subject to sedation in Pediatric Dentistry (Question 13).

After the questionnaires, the data were tabulated in IBM SPSS 25.0 program and evaluated by a descriptive analysis.

\section{RESULTS}

A positive response rate of $46.4 \%$ was obtained, corresponding to 66 interviewees. Regarding the general knowledge and professional profile of the interviewees, it was observed according to Table 1 that $36.4 \%$ were Pediatric Dentists for at least 10 years. About gender, the sample was predominantly female, $93.9 \%$. Considering the performance of these professionals, it was found that $59.1 \%$ work in public and private services. As Table 2 with regard to professional qualifications $78.8 \%$ had not done the course of sedation. Regarding the use of the sedation technique during dental care, $66.7 \%$ of the subjects mentioned that they did not use any form of sedation in their patients. When questioned regarding security before sedation means, $21.2 \%$ say they do not feel safe. It was also questioned the frequency, during all the professional career, with which professionals had used the technique of sedation and it was verified that $19.7 \%$ of the sample had to use the method more than four times.

The drugs already used, as shown in Table 3, it was observed that $15.2 \%$ of these professionals uses midazolam and chloral hydrate. The professionals' knowledge about the main advantages and disadvantages of using sedation in Pediatric Dentistry was questioned. It was verified that $37.9 \%$ of the respondents report as main advantage the possibility

Table 1: Distribution of the number of professionals according to professional characteristics.

\begin{tabular}{ccc}
\hline $\begin{array}{c}\text { Characteristics Expert } \\
\text { time (year) }\end{array}$ & $\mathbf{n}$ & $\%$ \\
\hline$<2$ & 08 & 12.1 \\
$2-4$ & 14 & 21.2 \\
$5-10$ & 24 & 36.4 \\
11 or + & 20 & 30.3 \\
Sex & & \\
Femal & 62 & 93.9 \\
Male & 04 & 6.1 \\
Workplace & & \\
Only private & 18 & 27.3 \\
Public & 09 & 13.6 \\
Public/Private & 39 & 59.1 \\
\hline
\end{tabular}

Table 2: Professional qualification and sedation practices.

\begin{tabular}{ccc}
\hline $\begin{array}{c}\text { Characteristics } \\
\text { Sedation course with } \\
\text { nitrous oxide }\end{array}$ & $\mathbf{n}$ & $\%$ \\
\hline Not & 52 & 78.8 \\
Yes & 14 & 21.2 \\
Uses sedation technique & 44 & 66.7 \\
Not & 22 & 33.3 \\
Yes & & \\
Feel safe when using & 14 & 21.2 \\
sedation & 13 & 19.7 \\
Not & 39 & 59.1 \\
Yes & & \\
They did not answer & 11 & 16.7 \\
Frequency of sedation & 13 & 19.7 \\
use & 42 & 63.6 \\
\hline to 3 times & \\
4 or + times & \\
They did not answer &
\end{tabular}

Table 3: Drugs used and specific knowledge of the practice of sedation.

\begin{tabular}{ccc}
\hline Characteristics & $\mathbf{n}^{\circ}$ & $\%$ \\
\hline Drugs & 10 & 15.2 \\
Midazolam & 10 & 15.2 \\
Cloral Hydrate & 09 & 13.7 \\
Diazepam & 08 & 12.1 \\
Nitrous oxide & & \\
Advantages of sedation & 25 & 37.9 \\
Possibility of conditioning & 18 & 27.3 \\
Simplicity of technique & 12 & 18.2 \\
Amnesia caused by the drug & & \\
Disadvantages of sedation & 27 & 40.9 \\
Unpredictability of drug effects & 23 & 34.8 \\
Adverse effects & 18 & 27.3 \\
Possibility of paradoxical effect & & \\
Risks of sedation & 28 & 42.4 \\
Allergic reactions to the sedative agent & 26 & 39.4 \\
Change in heart rate & 18 & 27.3 \\
Prolonged sedation & 15 & 22.7 \\
Paradoxical excitement & 05 & 7.6 \\
Aspiration of gastric contents & &
\end{tabular}

of conditioning. $40.9 \%$ of the sample points as negative points the unpredictability of drug effects. And about the main risks when performing sedation in children, it was evidenced that $42.4 \%$ of the sample indicated the possibility of occurrences of allergic reactions to the sedative agent.

\section{DISCUSSION}

The dental profession in Brazil, 40 years ago, could be considered as eminently masculine. Currently, the office has a female majority that accompanies the progressive enrollment of Brazilian women in higher 
education, especially since the $1980^{14}$ a similar indicator to that found in this study since we obtained that $93.9 \%$ of the professionals were female. In this study, the majority of professionals (59.1\%) have more than one labor relationship, working both in the public service and in the private service, which may mean that many dentists need more than one source of income for its survival, this, can also characterize the low remuneration of the specialist.

Currently the midazolam is the most used drug in Dentistry, especially in the management of infant patient, being effective to modify the behavior of children with mild to moderate anxiety level. ${ }^{16-18}$ In our study, $15.2 \%$ of Pediatric dentists reported using this drug in the practice of sedation; on the other hand, studies showed that benzodiazepine use was ineffective for effective control of non-collaboration behaviors with treatment, with no differences in the participants' level of collaboration, when compared to those who used placebo. ${ }^{3,4}$

Chloral Hydrate has been used for many years in Pediatric Dentistry throughout the world, due to the long experience of use, the method of easy application and the good acceptance by both the children and their parents. In this study $15.2 \%$ of the subjects reported administering chloral hydrate. The literature shows the efficacy of these drugs. ${ }^{19}$ However, it is worth noting that although there is no scientific evidence of the carcinogenic effect of chloral hydrate in humans, it is known that trichlorethylene, a chloral hydrate metabolite, has been mentioned as a potential carcinogenicity. ${ }^{20,21}$ Studies show that this drug causes chromosome changes, in vitro and in vivo, such as carninoma and adenocarcinoma hepatocellular antibodies in studies in guinea pigs ${ }^{22}$ Furthermore, this drug is potentially capable of causing unexpectedly deep sedation levels as well as upper airway obstruction in some patients. Thus, this drug is in disuse and replaced with more effective and safe agents. As a limitation of this study, the low representativeness of the sample prevents generalizations. Moreover, because it is a cross-sectional study, the professionals still mentioned the use of this drug and probably were not aware of the new drugs. ${ }^{23}$

In order to trace the profile of the professionals qualified in conscious sedation with nitrous oxide in the brazilian city of Porto Alegre, a study revealed that $40 \%$ were specialists in Pediatric Dentistry. ${ }^{24}$ Unlike the United States, about $90 \%$ of professionals routinely use the technique in Pediatric Dentistry. ${ }^{22}$

In this study it was observed that $42.4 \%$ of the subjects considered the possibility of occurrences of allergic reactions to the sedative agent as main risks, the literature points out that the indices of adverse effects reach $2.3 \%$ of the cases. ${ }^{25}$ Studies about the amnesic effects of drugs are seeking useful answers in the decision-making process on the best sedative to minimize memory of the event medical/dental and possible psychological trauma. ${ }^{26}$ According to the literature, some Pediatric Dentists, fearing some medical complication or the use of the technique, prefer not to sedate their patients, while others do not rely on conscious sedation techniques due to past failures. ${ }^{15}$ For the success of the technique, it is necessary the adequate training of the team, as well as the effective and constant monitoring of the cardiorespiratory functions and for this, it is important that the professional is prepared and has in the office all the necessary equipment to deal with eventual intercurrences and/or emergencies, in the guideline for sedation in children is recommended: pulse oximeter, oxygen balloon, expired carbon dioxide monitors, emergency kit, probes, suction catheter, facial mask and reversing medications. ${ }^{27,28}$

It is believed that up-to-date training and/or qualification, as well as a detailed history, observation of indications and contraindications, adequate medical advice and specific knowledge regarding medical emergencies and resuscitation measures, as well as drugs, therapeutic doses, side effects and antagonistic agents would reduce any complications.
Conscious or moderade sedation is becoming more common in pediatric patients undergoing minor procedures. ${ }^{28,29}$ It is noteworthy that sedation techniques of the child patient, although much discussed, still generate difficulties dilemmas and insecurities for professionals and thus, it is suggested to conduct new studies that address this theme.

\section{CONCLUSION}

It can be considered that the professionals involved had reasonable knowledge about sedation.

\section{ACKNOWLEDGEMENT}

We acknowledge all the pediatric dentists participants of this study.

\section{CONFLICT OF INTEREST}

The authors declare no conflict of interests.

\section{ABBREVIATIONS}

$\mathrm{N}_{2} \mathrm{O}$ : Nitrous oxide; CRO-CE: Regional Council of Dentistry; ICF: Informed Consent Form.

\section{REFERENCES}

1. Collars V, Caraciolo GM, Miranda AM, Araujo GB, War P. Fear and / or anxiety as an inhibitory factor for the visit to the dentist. Arch Donology. 2004;40(1):1 11.

2. Possobon RF, Carrascoz KC, Moraes ABA, Costa JAL. O tratamento odontológico como gerador de ansiedade. Psychol Study. 2007;12(3):609-16.

3. Possobon RF, Moraes BAA, Costa JAL, Ambrosano GMV. The behavior of children during dental care. Psychol Theory Res. 2003;19(1):59-64.

4. Possobon RF, Moraes BAA, Costa JAL, Ambrosano GMV. The behavior of children in dental treatment: Psychopharmacological intervention. Psychol Study. 2004;9(1):29-35

5. American Academy of Pediatric Dentistry. Clinical guideline on the elective use of minimal, moderate and deep sedation and anesthesia for pediatric denta patients. Pediatr Dent. 2005;27(67):105-17.

6. Ahmed SS, Hicks SR, Slaven JE, Nitu ME. Deep Sedation for Pediatric Dental Procedures: Is this a Safe and Effective Option?. J Clin Pediatr Dent. 2016;40(2):156-60

7. Ranali J, Ramacciato JC, Mota RHL. Biosafety in inhalation sedation with nitrous oxide. Rev Assoc Paul Cirur Dent. 2004;58(2):374-8.

8. Arnez MFM, Arnez MM, Queiroz AM, Stuani MBS, Silva FWGP. Conscious sedation: A pharmacological resource for the care of children and special patients. Pediatrics. 2011;33(2):107-16.

9. Gaujac C, Santos TH, Garção SM, Silva JJ, Brandão BCMRJ. Conscious sedation in dentistry. Rev De Odontol from Univ Cid Sao Paulo. 2009;21(3):251-7.

10. Barbosa AC, Mourão J, Miracle V, Andrade DC, Areias AC. Medicine Inhalation conscious sedation with nitrous oxide and/or oxygen in pediatric dentistry. Medicalexpress. 2014;1(3):102-4.

11. Rodrigues MLW, Rebouças PD. The use of benzodiazepines and $\mathrm{N}_{2} \mathrm{O} / \mathrm{O} 2$ in conscious sedation in Pediatric Dentistry. Faculty of Dentistry of Lins Journal 2015;25(1):55-9.

12. America Dental Association. Guidelines for the use of sedation and general anesthesia by dentists. 2007:1-13.

13. The Merican Academy of Publishing. American Academy of Pediatric Dentistry Guideline for monitoring and management of pediatric patients during and after sedation for diagnostic and therapeutic procedures. Pediatr Dent. 2012;34(6):94-210

14. Antunes DE, Viana KA, Costa PS, Costa LR. Moderate sedation helps improve future behavior in pediatric dental patients-a prospective study. Braz Oral Res. 2016;30(1):e107.

15. Nagano HCM. Dilemmas and reflections of pediatric dentists on child behavior management strategies. 85f. Thesis (Doctorate in Pediatric Dentistry) - Graduate Program in Dentistry, Federal University of Santa Catarina, Florianópolis. 2010.

16. Davidovich E, Meltzer L, Efrat J, Gozal D, Ram D. Post-Discharge events occurring after dental treatment under deep sedation in pediatric patients. J Clin Pediatr Dent. 2017;41(3):232-5.

17. Ahmed SS, Hicks SR, Slaven JE, Nitu ME. Deep Sedation for Pediatric Dental Procedures: Is this a Safe and Effective Option?. J Clin Pediatr Dent. 2016;40(2):156-60

18. Kip G, Turgut HC, Alkan M, Bani M, Arslan M. Clinical outcomes of different sedation techniques used in pediatric dentistry. Anaesthesia, Pain and Intensive 
Care. 2016;20(1):13-6.

19. Boswinkel JP, Litman RS. Sedating patients for radiologic studies. Pediatr Ann. 2005;34(1):650-4

20. Alsarheed MA. Intranasal sedatives in pediatric dentistry. Saudi Med J. 2016;37(9):948-56.

21. Smith MT. Chloral hydrate warning. Science. 1990;250(4979):359.

22. Haselkorn T, Whittemore AS, Udaltsova N, Friedman GD. Short-term chloral hydrate administration and cancer in humans. Drug Saf. 2006;29(1):67-77.

23. Salmon AG, Kizier KW, Zeise L, Jackson RJ, Smith MT. Potential carcionogenicity of chloral hydrate review. J Toxicol Clin Toxicol. 1995;33(2):115-21.

24. Tobias JD, Leder M. Procedural sedation: A review of sedative agents, monitoring and management of complications. Saudi J Anaesth. 2011;5(4):395-410.

25. Lorenz ACL, Chacon G, Kramer PF, Lima PVP. Profile of sedation utilization with nitrous oxide by dental surgeons in the city of Porto Alegre/RS. Stomatos.
2009;15(29):116-2

26. Pena BM, Krauss B. Adverse events of procedural sedation and analgesia in pediatric emergency department. Ann Emerg Med. 1999;34(4):483 -91.

27. Viana KA, Daher A, Maia LC, Costa PS, Martins CC, Paiva SM, et al. Memory effects of sedative drugs in children and adolescents-protocol for a systematic review. Syst Rev. 2016;5(1):34

28. American Academy off Pediatricntistry. Guideline for monitoring and management of patients before pediatric, during and after sedation for diagnostic and therapeutic procedures: 2016 Update. Pediatrics. 2016;38(4):3319.

29. Somri M, Matter I, Hadjittofi C, Hoash N, Moaddi B, Kharouba J, et al. Detection of respiratory adverse events in pediatric dental patients sedated with $0.75 \mathrm{mg} / \mathrm{kg}$ of midazolam and oxygen by continuous pretracheal auscultation: A prospective randomized controlled trial. J Clin Pediatr Dent. 2017;41(2):154 60.

Article History: Submission Date : 15-05-2019; Revised Date : 21-08-2019; Acceptance Date : 23-08-2019.

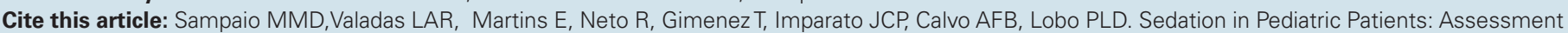
of Pediatric Knowledge. J Young Pharm. 2019;11(4):382-5. 